\title{
Accelerated Allogeneic Haemopoietic Engraftment after Preceding Rituximab-Therapy
}

\author{
William H. Krüger*, Thomas Kiefer, Christian Lotze, Fabian P. Thomsen, Carsten Hirt, Frank \\ Schüler, Christoph Busemann and Gottfried Dölken
}

Department of Internal Medicine C - Haematology and Oncology, Stem Cell Transplantation, Ernst-Moritz-Arndt-
University, Greifswald, Germany

\begin{abstract}
The chimeric monoclonal anti-CD20 antibody rituximab and the graft-versus-leukaemia/lymphoma effect after allogeneic stem cell transplantation have improved therapy of lymphatic malignancies during the last decade. In addition, successful therapy of chronic graft-versus-host disease after stem cell transplantation with rituximab has been published. Other investigators correlated prolonged neutropenia after autologous stem cell transplantation with prior rituximabtherapy.

To address the question, if rituximab pre-treatment prior to transplantation diminishes the graft versus lymphoma effect afterwards and can prolong engraftment of allogeneic haemopoiesis, we retrospectively analysed data from 34 patients allografted for lymphoid malignancies. 19 patients had received at least one course of rituximab prior to allogeneic stem cell transplantation and 15 did not. Both groups matched very good.

Patients with rituximab pre-treatment engrafted with 1 leukocyte/nl significantly faster than patients without prior rituximab therapy (12 days [median, range 1-32] vs. 18 days [median, range 12-31], p<0,005). Engraftment of platelets (PLT) occurred as well faster after rituximab pre-treatment. The differences were significant for all three steps [20PLT/nl: 11,5 days (median, range 1-28) vs. 27 days (median, range 11-54) $\mathrm{p}<0,001 ; \mathbf{5 0 P L T} / \mathbf{n l}: 16,5$ days (median, range 11-37) vs. 42 days (median, range 22-70) p<0,001; 100PLT/nl: 22,5 days (median, range 13-52) vs. 60 days (median, range 25-117) $\mathrm{p}<0,005]$. The mechanism leading to faster engraftment remains unclear so far. Preceding therapy with rituximab had no influence on event-free survival, overall survival, or manifestation freedom from graft-versus-host disease (GVHD) after allogeneic stem cell transplantation. Patients with GVHD had a significantly better overall survival $(\mathrm{p}=0,0001)$ comparing to patients without.

In conclusion, this investigation gives no hint for a suppression of $\mathrm{GvH}$ and $\mathrm{GvL}$ effects by rituximab administration prior to allogeneic stem cell transplantation. In addition, in contrast to results published for autologous stem cell transplantation, no detrimental effects on establishment of graft haemopoiesis after allogeneic stem cell transplantation by preceding rituximab therapy were found.
\end{abstract}

Key Words: Allogeneic stem cell transplantation, Haemopoietic engraftment, Rituximab, Graft-versus-host-disease, Graftversus-leukaemia effect.

\section{INTRODUCTION}

The introduction of the chimeric monoclonal anti-CD20 antibody rituximab has become a landmark in therapy of Bcell derived non-Hodgkin's lymphoma [1, 2]. However, a considerable percentage of patients may relapse even after combined immunochemotherapy with or without subsequent consolidation by high-dose therapy and autologous stem cell reinfusion. Allogeneic stem cell transplantation is a potentially curative salvage therapy for these patients [3-5]. Myeloablative conditioning regimen used in earlier approaches were associated with significant morbidity and mortality, especially in elderly or heavily pre-treated patients [6]. Allogeneic stem cell transplantation using reduced intensity

\footnotetext{
*Address correspondence to this author at the Medizinische Klinik C (Hämatologie und Onkologie, Transplantationszentrum), Ernst-MoritzArndt-Universität Greifswald, Ferdinand-Sauerbruch-Straße, 17475 Greifswald, Germany; Tel: +49-3834-86-22007/22006; Fax: +49-3834-86-22012; E-mail: william.krueger@uni-greifswald.de
}

(RIC) conditioning protocols is a promising and potentially curative approach for patients after failure of conventional therapy since the results of transplantation for lymphoma have improved dramatically over the last decade $[4,6,7]$.

Substantial contribution of graft-versus-leukaemia/lymphoma effect to eradication of minimal residual disease after allogeneic haemopoietic cell transplantation has been described by a variety of investigators. A considerable percentage of patients require donor lymphocyte infusions (DLI) after transplantation for definite eradication of the malignant clone, however, this approached bears an increased risk of acute or chronic graft-versus-host disease [4, 8-10].

Some concern is raised by publications describing activity of rituxmab against chronic graft-versus-host disease [1113]. Here the question must be addressed, if pre-treatment with rituximab can diminish GvHD and graft-versuslymphoma effect after allografting. This situation can not be easily compared with successful rituximab-therapy of mini- 
mal residual disease after allogeneic SCT, since here an engraftment and partial expansion of transplanted lymphopoiesis took place [14].

In addition, rituximab has been suspected to have detrimental effects on leukocyte engraftment after autologous stem cell transplantation $[15,16]$. Since rapid leukocyte engraftment is essential to circumvent serious infectious complications, this is another critical point of rituximab pretreatment of candidates for allogeneic stem cell transplantation.

To address both questions we have retrospectively analysed our data of allogeneic transplantation of patients with lymphoid malignancies and compared data from patients with a history of rituximab therapy with data from patients not exposed to the antibody.

\section{PATIENTS AND METHODS}

\section{Patients}

The data from thirty-four consecutive patients allografted for high-risk lymphoid malignancies were included in this investigation (Table 1). Twenty-seven patients were male $(79,4 \%)$ and seven patients $(20,6 \%)$ were female. The median age at the time of stem cell transplantation was 46 years (range 22-67). The underlying diagnoses were high-grade non-Hodgkin's lymphoma $(\mathrm{n}=14,41,2 \%)$, acute lymphoblastic leukaemia $(n=8,23,5 \%)$, chronic lymphocytic leukaemia $(n=6,17,7 \%)$, mantle cell lymphoma $(n=3,8,8 \%)$, multiple myeloma $(n=2,5,9 \%)$, and variant hairy cell leukaemia $(n=1$, $2,9 \%)$. The vast majority of lymphomas was B-cell derived $(\mathrm{n}=30,88,2 \%)$

All patients were at highest risk for relapse and had no curative option by conventional chemotherapy or autologous stem cell transplantation. At the time of allogeneic transplantation, five patients were in first $(14,7 \%)$, nine $(26,5 \%)$ in second, and two $(5,9 \%)$ in third or higher complete remission. Six $(17,7 \%)$ patients each had either a partial remission or progressive or relapsing disease. The patients were heavily pre-treated with a median of seven cycles chemotherapy (range 2-37) of three (median, range 1-10) different regimens. Additionally, 12 patients $(35,3 \%)$ had a history of prior myeloablative therapy followed by autologous $(n=9)$ or allogeneic $(n=3)$ haemopoietic cell transplantation.

\section{History of Rituximab Pre-Treatment}

Nineteen $(55,9 \%)$ patients had a history of pre-treatment with rituximab. At median 4 (range 1-10) doses of $375 \mathrm{mg} / \mathrm{m}^{2}$ of the chimeric antibody were given. The median cumulative dose was $1500 \mathrm{mg} / \mathrm{m}^{2}$ with a range from $375 \mathrm{mg} / \mathrm{m}^{2}$ to $3750 \mathrm{mg} / \mathrm{m}^{2}$. The median interval from the last rituximab infusion to allogeneic transplantation was 5,9 weeks (range 0,1-212,9). Since Edwards et al. published a complete B-cell depletion by rituximab for more than 25 weeks without upcoming recovery and Leandro et al. described B-cell depletion for more than four years in a patient with lupus erythematodes after Rituximab-treatment, we decided not to exclude the single patient with the interval of 212,9 weeks from analysis $[17,18]$. Patients with and without a history of rituximab-pre-treatment matched very well without significant differences in all relevant parameters (Table $\mathbf{1}$ ).

\section{Transplantation and Supportive Care}

The thirty-four patients were allografted 16 months (median, range 1-124) after initial diagnosis from related $(n=13)$ and unrelated $(n=21)$ donors. The donors were fully matched with the exception of one major-mismatch in a related transplantation. Twenty-five $(73,5 \%)$ of the patients and 17 $(50,0 \%)$ of the stem cell donors had prior exposition to human cytomegalovirus as indicated by IgG. Three male patients were grafted from a female donor.

Conditioning regimens were myeloablative in 8 patients $(23,5 \%)$ and toxicity-reduced in 26 patients $(76,5 \%)$. Myeloablative regimen were Busulfan ${ }_{16} /$ Cyclophosphamid $_{120}(\mathrm{n}=7$, $20.6 \%)$ and $\mathrm{TBI}_{12 \mathrm{~Gy}} /$ Cyclophosphamid ${ }_{120}(\mathrm{n}=1,2,9 \%)$. For toxicity reduced conditioning were Treosulfan/Fludarabin $(\mathrm{n}=17,50,0 \%)$, Busulfan/Fludarabin $(\mathrm{n}=5,14,7 \%)$, and TBI $(2 G y) / F l u d a r a b i n ~(n=2,5,9 \%)$ chosen [19-21]. All patients were grafted with non-manipulated G-CSF mobilised peripheral blood stem cells. Given was a median dose of $5,7 * 10^{6}$ (range $0,9-13,9$ ) CD $34^{+}$cells per $\mathrm{kg}$ bodyweight. Antithymocyte globuline was given when no HLA-identical sibling donor was available for stem cell donation.

Patients with and without prior rituximab-exposition matched excellent with exception of the constellation of CMV-negative donors for CMV-positive patients, which occurred significantly more in the rituximab pre-treated group (Table $\mathbf{1}$ ).

Haemopoiesis was stimulated with G-CSF until leukocyte-engraftment after transplantation. Antimicrobial prophylaxis with quinolones, antimycotics and virustatics as well as Pneumocystis jrovecii prophylaxis followed standard procedures [22]. GVHD prophylaxis was carried out with methotrexate and cyclosporine-A following standard protocols. Additional mycophenolate mofetil was given after conditioning with 2Gy TBI [21]. Acute and chronic GVHD were treated with steroids according to standard protocols [23, 24]. Donor-lymphocyte transfusions (median 3, range 1-5) were given to six $(17,7 \%)$ patients for molecular or clinical relapse.

\section{Assessement of Outcome}

Leukocyte engraftment was defined as the first of 3 consecutive days that the absolute leukocyte count exceeded 1,0 cells per nl of blood and steps of platelet count recovery were defined as the first day that the platelet count exceeded 20, 50 and 100 platelets per nl of blood, respectively, independent of platelet transfusions. Acute and chronic GVHD were graded following the published criteria [25-27].

Survival was calculated using the log-rank test and the Kaplan-Meyer analysis. Event-free survival (EFS) and overall survival (OS) are defined as intervals from day of transplantation until lost of follow-up or relapse not treated successfully with donor-lymphocyte transfusions (EFS) or death (OS).

\section{Data Collection and Statistics}

Data were collected and analysed using the softwares MS-Excel (Microsoft, Munich, Germany) and GraphPad Prism (GraphPad Software, San Diego, CA, USA). Statistical tests are mentioned where appropriate. 
Table 1. Patients Characteristics. Given are Either the Number (n) and Percentage or Median and Range

\begin{tabular}{|c|c|c|c|c|}
\hline Gender male & $16(84,2 \%)$ & $11(73,3 \%)$ & 0,36 & Fisher's exact $\mathrm{p}$ \\
\hline High-grade malignancy & $12(63,2 \%)$ & $10(66,7 \%)$ & 0,56 & Fisher's exact $\mathrm{p}$ \\
\hline Remission state at TX & $\begin{array}{c}\text { CR } 8 \\
\text { PR } 7 \\
\text { RD/PD } 4\end{array}$ & $\begin{array}{c}\text { CR } 8 \\
\text { PR } 6 \\
\text { RD/PD } 1\end{array}$ & 0,49 & Chi-square \\
\hline Preceding CTX regimens & $3(2-10)$ & $3(1-5)$ & 0,29 & U-test (Mann-Whitney) \\
\hline Preceding CTX cycles & $8(4-37)$ & $7(2-21)$ & 0,43 & U-test (Mann-Whitney) \\
\hline Female donor $\Rightarrow$ male patient & $9(47,4 \%)$ & $2(13,3 \%)$ & 0,04 & Fisher's exact $p$ \\
\hline $\mathrm{CMV}^{\text {neg }}$-donor $\Rightarrow \mathrm{CMV}^{\mathrm{pos}}$-patient & $3(13,8 \%)$ & 0 & 0,16 & Fisher's exact $\mathrm{p}$ \\
\hline Donor-type mud & $11(57,9 \%)$ & $10(66,7 \%)$ & 0,44 & Fisher's exact $p$ \\
\hline Use of ATG in conditioning & $11(57,9 \%)$ & $12(80,0 \%)$ & 0,16 & Fisher's exact $p$ \\
\hline RIC & $13(68,4 \%)$ & $13(86,7 \%)$ & 0,20 & Fisher's exact $p$ \\
\hline $2^{\text {nd }} \mathrm{TX}$ & $8(42,1 \%)$ & $3(20,0 \%)$ & 0,16 & Fisher's exact $\mathrm{p}$ \\
\hline $\mathrm{CD} 34^{+}$-cells $\left(10^{6} / \mathrm{kg}\right)$ & $5,3(1,6-13,9)$ & $6,4(0,9-11,4)$ & 0,67 & U-test (Mann-Whitney) \\
\hline $\begin{array}{l}\text { Time from primary diagnosis to } \\
\text { transplantation (months) }\end{array}$ & $24,1(2,9-123,5)$ & $14,3(1,0-67,0)$ & 0,66 & U-test (Mann-Whitney) \\
\hline
\end{tabular}

Abbreviations: ALL: acute lymphoblastic leukaemia, CLL: chronic lymphocytic leukaemia, HCL: hairy-cell leukaemia, MM: multiple myeloma, NHL: non-Hodgkin's lymphoma, CR: complete remission, PD: progressive disease, PR: partial remission, REL: relapse, CTX: chemotherapy, ATG: anti-thymocyte globulin, CMV: cytomegalovirus, RIC: reducedintensity conditioning, TX: transplantation.

\section{RESULTS}

\section{Engraftment}

Thirty-two patients $(94,1 \%)$ engrafted with 1 leukocyte/nl 15 days (median, range 1-32 days) after transplantation. Patients with rituximab pre-treatment reached 1 leukocyte/nl significantly faster than patients without prior rituximab therapy (11,5 days [median, range 1-32] vs. 18 days [median, range 12-31, p <0,005, Mann-Whitney U-test) (Table 2).
Engraftment of platelets (PLT) with 20/nl was reached by 29 patients $(85,3 \%) 17$ days (median, range 1-54 days) after transplantation; 50 platelets/nl and 100 platelets/nl were reached by 23 patients $(67,7 \%)$ after 25 days (median, range 11-70) and 31 days (median, range 13-117) after transplantation. Engraftment of platelets occurred as well faster after rituximab pre-treatment. The differences were significant for all three steps (20PLT: 11,5 days (median, range 1-28) vs. 27 days (median, range $11-54) \mathrm{p}<0,001 ;$ 50PLT: 16,5 days (median, range 11-37) vs. 42 days (median, range 22-70)

Table 2. Engraftment of Leukocytes (WBC) and Platelets (PLT). Given is the First of Three Consecutive Days after Stem Cell Transplantation that the Absolute Leukocyte Count Exceeded 1,0 Cells Per nl of Blood and Steps of Platelet Count Recovery were Defined as the First Day that the Platelet Count Exceeded 20, 50 and 100 Platelets Per nl of Blood, Respectively, Independent of Platelet Transfusions. P-Values were Calculated Using the Mann-Whitney U-Test

\begin{tabular}{|c|c|c|c|}
\hline $\mathrm{WBC}>1 / \mathrm{nl}$ (day) & $12(1-32)$ & $18(12-31)$ & $<0,005$ \\
\hline PLT $>50 / \mathrm{nl}$ (day) & $16,5(11-37)$ & $42(22-70)$ & $<0,001$ \\
\hline PLT $>100 / n l$ (day) & $22,5(13-52)$ & $60(25-117)$ & $<0,005$ \\
\hline
\end{tabular}


$\mathrm{p}=0,001$; 100PLT: 22,5 days (median, range 13-52) vs. 60 days (median, range 25-117) $\mathrm{p}<0,005$; Mann-Whitney Utest) (Table 2). Scatter diagrams for time to engraftment of leuocytes and platelets in relation to the grafted $\mathrm{CD} 34^{+}$-cell dose are shown in Fig. (1). The CD34+-cell dose was identical in both collectives with a median dose of 5,3 (range: 1,6$13,9)^{*} 10^{6} \mathrm{CD} 34^{+}$-cells $/ \mathrm{kg}$ in the patients with exposition to rituximab and 6,4 (range: $0,9-11,4) * 10^{6} \mathrm{CD} 34^{+}$-cells $/ \mathrm{kg}$ in rituximab-naïve patients. In addition, Fig. (1) shows that the differences can not be put down on the stem cell dose.

The risk to fail engraftment with leukocytes or platelets at any step was slightly but non-significant increased for patients who did not receive rituximab prior to allogeneic stem cell transplantation (data not shown).

\section{Graft-Versus-Host Disease}

The overall-incidence of acute graft versus host disease was $52,9 \%(\mathrm{n}=18)$ in all patients. Differences between patients with and without rituximab pre-treatment were not seen $(11 / 19$ [57,9\%] vs. 7/15 [46,7\%]). Overall, nine patients
(26,5\%) suffered from acute liver GVHD, 17 patients $(50,0 \%)$ from acute GVHD of the skin and 14 patients $(41,2 \%)$ from acute GVHD of the gastrointestinal tract. The median stages of acute GVHD for liver, skin and gut were 0 (range 0-3), 0,5 (0-4) and 0 (0-4), respectively. Three patients $(8,8 \%)$ developed grade IV acute GVHD. Grade III and II acute GVHD was seen in seven $(20,6 \%)$ cases each and one $(2,9 \%)$ patient suffered from grade I GVHD, respectively. Obvious differences between both groups of patients were not observed.

The overall incidence of chronic GVHD was $38,2 \%$ (13/34) after an interval of 6,8 (median, range 2,2-20,0) months. Eight $(23,5 \%)$ suffered from extensive disease and five $(14,7 \%)$ from limited stage chronic GVHD. Within subgroups, cGVHD-incidence was $26,7 \%$ (4/15) without and $47,4 \%(9 / 19)$ after prior rituximab-exposition. There was a trend that chronic graft versus host disease did manifest earlier in patients not exposed to rituximab, however, without statistical significance (median 5,1, range 3,0-9,5 months vs. 9,9 , range 2,2-20,0 months, n.s.).
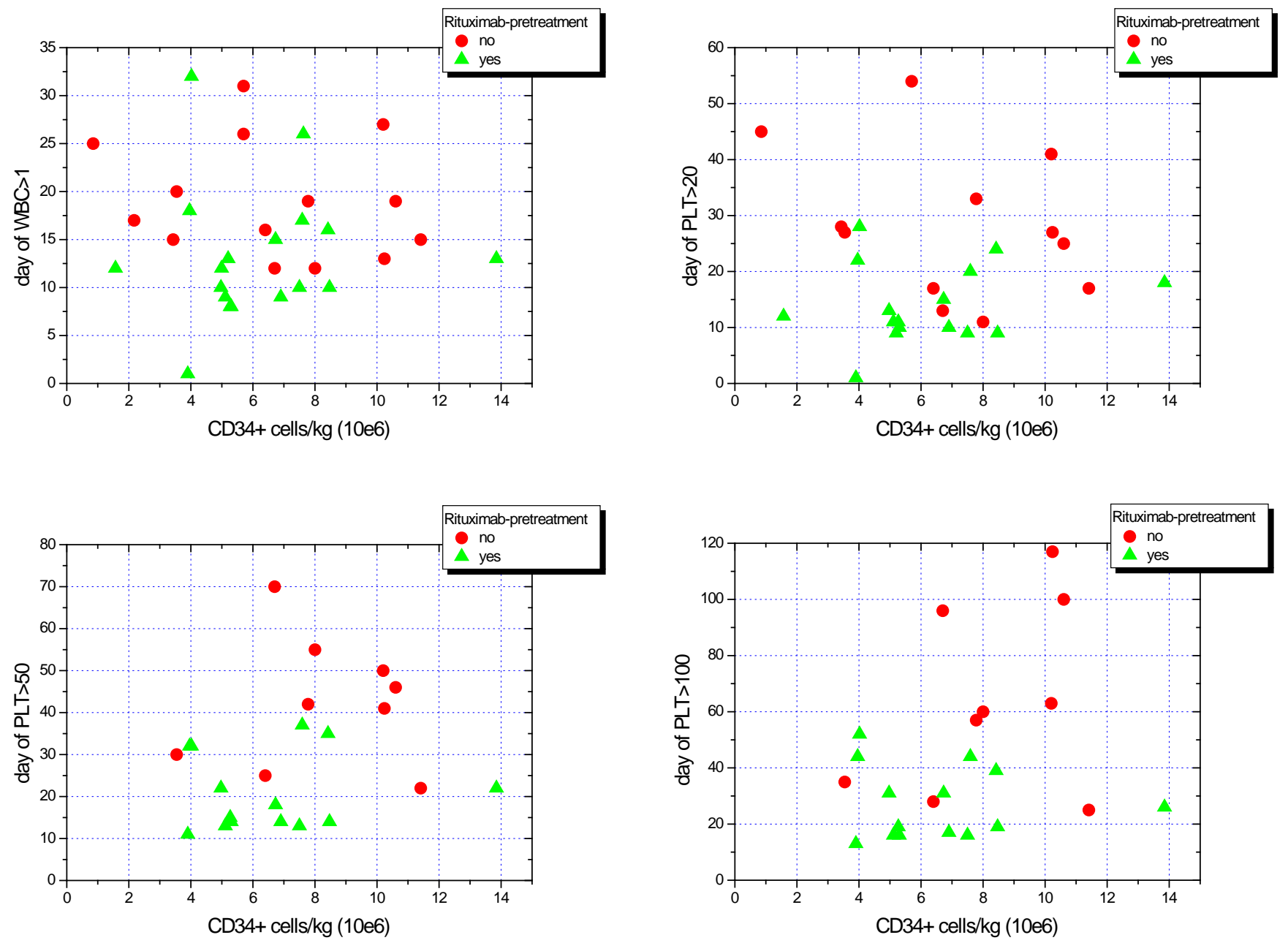

Fig. (1). Scatter-diagrams of engraftment of white blood cells (WBC) with a count of 1 cell/nl and of platelets with 20,50 and 100 per nl in relation to the transplanted $\mathrm{CD}_{3} 4^{+}$cell dose per kilogram bodyweight of the recipient (x-axis). The y-axis shows the first day of three consecutive days after transplantation on which the cell count was reached independently from transfusions. 
To exclude any bias from other events such as transplantrelated mortality or mortality due to relapse, the interval freedom from GVHD was calculated using log-rank test and Kaplan-Meyer curves. The endpoints were manifestation of GVHD, the day of last follow-up or death. The curves for freedom from any GVHD are shown Fig. (2). The median interval 'freedom from any GVHD' was 2,2 months without and 1,1 months after rituximab pre-treatment. The curves from separate analyses for acute and chronic GVHD are also strictly in parallel (data not shown).

\section{Survival and Outcome}

Thirteen $(38,2 \%)$ of the patients are alive after a median follow-up was 8,8 months with a range from 0,1 to 72,9 months. Twenty-one $(61,8 \%)$ patients have died from relapse $(\mathrm{n}=6,17,7 \%)$, acute GVHD $(\mathrm{n}=2,5,9 \%)$, chronic GVHD $(n=3,15,8 \%)$, infection $(n=5,14,7 \%)$, EBV-lymphoproliferative disease $(n=2,5,9 \%)$ multi-organ failure, secondary cancer and bleeding (each $n=1,2,9 \%$ ). Pre-treatment with rituximab had neither impact on event-free or overall sur- vival nor on manifestation of GVHD after stem cell transplantation (Fig. 2). However, overall survival was significantly improved by manifestation of acute GVHD ( $p=0,02$, log-rank test), chronic GVHD ( $p<0,01$, log-rank test) or any form of GVHD ( $p=0,001$, log-rank test). The median overall survival was 2,3 months (range 0,1-33,8 months) without GVHD comparing to 14,5 months (median, range 0,6-72,9 months) in patients with acute, chronic or both forms of GVHD (Fig. 2).

\section{DISCUSSION}

The surprising result of the present retrospective investigation is the significant faster engraftment of white blood cells and platelets in patients treated with rituximab prior to stem cell transplantation compared to engraftment in rituximab-naïve patients. Despite the small sample size of $n=34$, the differences are consistently of high significance always with $\mathrm{p}<0,005$. There were no differences in the patient characteristics predicting a slower engraftment in rituximabnaïve patients. These patients were more frequently condi-
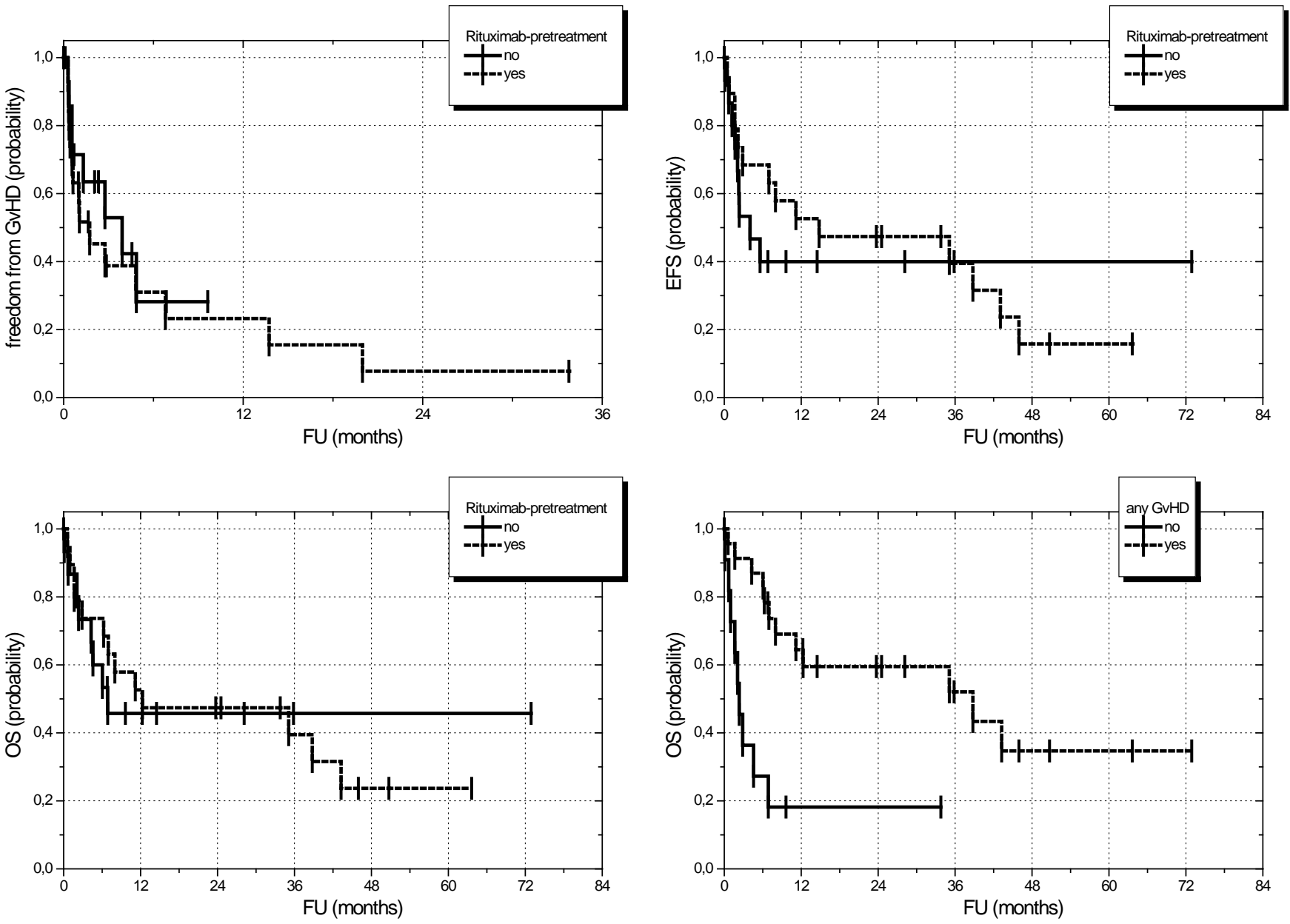

Fig. (2). Kaplan-Meyer plots for patients with and without rituximab-pretreatment, follow-up time is shown in months. Shown are the curves for freedom-from-GvHD (top-left) (n.s.), event-free survival (EFS, top-right) (n.s.), and overall survival (OS, bottom-left) (n.s.). The diagram at the bottom right shows overall survival curves for patients with manifestation of acute and/or chronic graft versus host disease (GvHD) comparing to patients without any GvHD ( $\mathrm{p}=0,001)$. 
tioned with reduced intensity regimen, have been grafted with a slightly higher CD34 $4^{+}$-cell dose and were slightly less heavily pre-treated as the rituximab-positive patients [28]. In addition, they were less frequently CMV-seropositive than the patients from the rituximab-collective [29]. However, all these differences were statistically non-significant. The observed results suggest inhibition of allogeneic leukocyte and platelet engraftment by $\mathrm{CD} 20$-antigene positive cell populations, either host or donor derived, with facilitation of engraftment after in-vivo depletion of these cells by Rituximab. No comparable results have been published so far.

Rituximab has been used with success for therapy of antibody-mediated thrombocytopenia and haemolysis after allogeneic transplantation and in other situations [30-32]. In addition, the successful treatment of chronic GVHD with rituximab as reported by Rathanatarathorn and Cutler suggests interaction of $\mathrm{CD} 20^{+}$cells with cellular immune response [11-13].

Interaction of rituximab with engraftment has been described after high-dose therapy and autologous stem cell transplantation, however, there is some inconsistency in these results. Benekli et al. described a lower yield of $\mathrm{CD} 34^{+}$-cell in stem cell harvests and delay of leukocyte engraftment after rituximab pre-treatment. Hoerr et al. described delayed platelet engraftment but no detrimental effects on stem cell mobilisation and Buckstein et al. and Hosing et al. observed also no affection of stem cell moblisation [33-35]. Cairoli et al. and Lemieux et al. have observed late onset cytopenia after rituximab-treatment after autologous stem cell transplantation $[15,16]$. Few data have been published for allogeneic transplantation so far. Khouri et al. have included rituximab into dose- reduced conditioning for chronic lymphocytic leukaemia and administered additional doses after SCT for elimination of minimal disease [14]. However, comparison of engraftment was not subject of their analysis. From the present and other investigations it can be concluded, that $\mathrm{CD} 20^{+} \mathrm{B}$-cells play a role in engraftment after stem cell transplantation and further clinical and basic research for clarification of the mechanisms is necessary.

The present investigation gives no evidence for suppression of acute or chronic GVHD by rituximab-treatment prior to allogeneic stem cell transplantation since the curves for freedom from GVHD are strictly in parallel. This is even true for manifestation of acute and chronic GVHD alone. In addition, rituximab-therapy prior to allogeneic stem cell transplantation did not influence overall survival after SCT (Fig. 2). It is very difficult to explain these observations in context with those of effective GVHD-treatment by rituximab when infused after SCT, especially since the research on immune recovery after allogeneic SCT has focused on Tcells so far [36]. Possible mechanisms might be such as differences in the amount of circulating anti-CD20 antibodies, the relation between host and donor derived B-cells, and the extent of upcoming immune tolerance. The observation by Hedge et al., that rituximab-treatment of fludarabin-associated immune-thrombopenia in CLL patients is effective, suggests an important role of T-lymphocytes in regulation of Bcell-(antibody)-mediated cytopenia [37].

In conclusion, there we did not found any concern against rituximab-therapy prior to planned allogeneic stem cell transplantation since it has no detrimental effects on allogeneic engraftment, it does not diminish manifestation of graftversus-host disease and there is even no evidence for negative effects on graft-versus-lymphoma effects. The manifestation of graft-versus-host disease remains highly significant associated with a superior outcome compared to patients without GVHD as described for allogeneic transplantation of patients with other entities $[8,38]$. The observed acceleration of allogeneic engraftment in this retrospective analysis should be comfirmed in a prospective trial.

\section{ACKNOWLEDGEMENTS}

We wish to thank the nurses for their excellent patient care.

\section{REFERENCES}

[1] Coiffier B, Lepage E, Briere J, et al. CHOP chemotherapy plus rituximab compared with $\mathrm{CHOP}$ alone in elderly patients with diffuse large-B-cell lymphoma. N Engl J Med 2002; 346(4): 235-42.

[2] Hiddemann W, Dreyling M, Unterhalt M. Rituximab plus chemotherapy in follicular and mantle cell lymphomas. Semin Oncol 2003; 30(1 Suppl 2): 16-20.

[3] van Besien KW, Mehra RC, Giralt SA, et al. Allogeneic bone marrow transplantation for poor-prognosis lymphoma: response, toxicity and survival depend on disease histology. Am J Med 1996; 100(3): 299-307.

[4] Escalon MP, Champlin RE, Saliba RM, et al. Nonmyeloablative allogeneic hematopoietic transplantation: a promising salvage therapy for patients with non-Hodgkin's lymphoma whose disease has failed a prior autologous transplantation. J Clin Oncol 2004; 22(12): 2419-23.

[5] Khouri IF, Saliba RM, Giralt SA, et al. Nonablative allogeneic hematopoietic transplantation as adoptive immunotherapy for indolent lymphoma: low incidence of toxicity, acute graft-versus-host disease, and treatment-related mortality. Blood 2001; 98(13): 35959.

[6] Robinson SP, Goldstone AH, Mackinnon S, et al. Chemoresistant or aggressive lymphoma predicts for a poor outcome following reduced-intensity allogeneic progenitor cell transplantation: an analysis from the Lymphoma Working Party of the European Group for Blood and Bone Marrow Transplantation. Blood 2002; 100(13): 4310-6.

[7] Bertz H, Illerhaus G, Veelken H, et al. Allogeneic hematopoetic stem-cell transplantation for patients with relapsed or refractory lymphomas: comparison of high-dose conventional conditioning versus fludarabine-based reduced-intensity regimens. Ann Oncol 2002; 13(1): 135-9.

[8] Kolb HJ, Schmid C, Barrett AJ, et al. Graft-versus-leukemia reactions in allogeneic chimeras. Blood 2004; 103(3): 767-76.

[9] Corradini P, Dodero A, Zallio F, et al. Graft-versus-lymphoma effect in relapsed peripheral T-cell non-Hodgkin's lymphomas after reduced-intensity conditioning followed by allogeneic transplantation of hematopoietic cells. J Clin Oncol 2004; 22(11): 2172-6.

[10] Grigg A, Ritchie D. Graft-versus-lymphoma effects: clinical review, policy proposals, and immunobiology. Biol Blood Marrow Transplant 2004; 10(9): 579-90.

[11] Cutler C, Miklos D, Kim HT, et al. Rituximab for steroidrefractory chronic graft-versus-host disease. Blood 2006; 108(2): 756-62.

[12] Okamoto M, Okano A, Akamatsu S, et al. Rituximab is effective for steroid-refractory sclerodermatous chronic graft-versus-host disease. Leukemia 2006; 20(1): 172-3.

[13] Ratanatharathorn V, Ayash L, Reynolds C, et al. Treatment of chronic graft-versus-host disease with anti-CD20 chimeric monoclonal antibody. Biol Blood Marrow Transplant 2003; 9(8): 505-11.

[14] Khouri IF, Lee MS, Saliba RM, et al. Nonablative allogeneic stem cell transplantation for chronic lymphocytic leukemia: impact of rituximab on immunomodulation and survival. Exp Hematol 2004; 32(1): 28-35.

[15] Cairoli R, Grillo G, Tedeschi A, et al. High incidence of neutropenia in patients treated with rituximab after autologous stem cell transplantation. Haematologica 2004 ; 89(3): 361-3. 
[16] Lemieux B, Tartas S, Traulle C, et al. Rituximab-related late-onset neutropenia after autologous stem cell transplantation for aggressive non-Hodgkin's lymphoma. Bone Marrow Transplant 2004; 33(9): 921-3.

[17] Edwards JC, Szczepanski L, Szechinski J, et al. Efficacy of B-celltargeted therapy with rituximab in patients with rheumatoid arthritis. N Engl J Med 2004; 350(25): 2572-81.

[18] Leandro MJ, Cambridge G, Edwards JC, et al. B-cell depletion in the treatment of patients with systemic lupus erythematosus: a longitudinal analysis of 24 patients. Rheumatology (Oxford) 2005; 44(12): 1542-5.

[19] Casper J, Knauf W, Kiefer T, et al. Treosulfan and fludarabine: a new toxicity-reduced conditioning regimen for allogeneic hematopoietic stem cell transplantation. Blood 2004; 103(2): 725-31.

[20] Kroger N, Schetelig J, Zabelina T, et al. A fludarabine-based dosereduced conditioning regimen followed by allogeneic stem cell transplantation from related or unrelated donors in patients with myelodysplastic syndrome. Bone Marrow Transplant 2001; 28(7): 643-7.

[21] Niederwieser D, Maris M, Shizuru JA, et al. Low-dose total body irradiation (TBI) and fludarabine followed by hematopoietic cell transplantation (HCT) from HLA-matched or mismatched unrelated donors and postgrafting immunosuppression with cyclosporine and mycophenolate mofetil (MMF) can induce durable complete chimerism and sustained remissions in patients with hematological diseases. Blood 2003; 101(4): 1620-9.

[22] Kruger WH, Bohlius J, Cornely OA, et al. Antimicrobial prophylaxis in allogeneic bone marrow transplantation. Guidelines of the Infectious Diseases Working Party (AGIHO) of the German Society of Haematology and Oncology. Ann Oncol 2005; 16(8): 138190

[23] Lazarus HM, Vogelsang GB, Rowe JM. Prevention and treatment of acute graft-versus-host disease: the old and the new. A report from the Eastern Cooperative Oncology Group (ECOG). Bone Marrow Transplant 1997; 19(6): 577-600.

[24] Vogelsang GB. How I treat chronic graft-versus-host disease. Blood 2001; 97(5): 1196-201.

[25] Glucksberg H, Storb R, Fefer A, et al. Clinical manifestations of graft-versus-host disease in human recipients of marrow from HLA-matched sibling donors. Transplantation 1974; 18(4): 295-304

[26] Shulman HM, Sullivan KM, Weiden PL, et al. Chronic graftversus-host syndrome in man. A long-term clinicopathologic study of 20 Seattle patients. Am J Med 1980; 69(2): 204-17.
[27] Lee SJ, Klein JP, Barrett AJ, et al. Severity of chronic graft-versushost disease: association with treatment-related mortality and relapse. Blood 2002; 100(2): 406-14.

[28] Baron F, Little MT, Storb R. Kinetics of engraftment following allogeneic hematopoietic cell transplantation with reduced-intensity or nonmyeloablative conditioning. Blood Rev 2005; 19(3): 153-64.

[29] Kroger N, Zabelina T, Kruger W, et al. CMV-seropositivity of the patient with or without reactivation is the most important prognostic factor for survival and treatment-related mortality in stem cell transplantation from unrelated donors using pre-transplant in vivo T-cell depletion with ATG. In: Schultze W, Ed. High-dose therapy and transplantation of haematopoietic stem cells (2001). $1^{\text {st }}$ ed. Berlin, Vienna: Blackwell Verlag 2002. pp. 47-60.

[30] Faurschou M, Hasselbalch HC, Nielsen OJ. Sustained remission of platelet counts following monoclonal anti-CD20 antibody therapy in two cases of idiopathic autoimmune thrombocytopenia and neutropenia. Eur J Haematol 2001; 66(6): 408-11.

[31] Heelan BT, Tormey V, Amlot P, et al. Effect of anti-CD20 (rituxi$\mathrm{mab}$ ) on resistant thrombocytopenia in autoimmune lymphoproliferative syndrome. Br J Haematol 2002 ; 118(4): 1078-81.

[32] Raj K, Narayanan S, Augustson B, et al. Rituximab is effective in the management of refractory autoimmune cytopenias occurring after allogeneic stem cell transplantation. Bone Marrow Transplant 2005; 35(3): 299-301.

[33] Hoerr AL, Gao F, Hidalgo J, et al. Effects of pretransplantation treatment with rituximab on outcomes of autologous stem-cell transplantation for non-Hodgkin's lymphoma. J Clin Oncol 2004; 22(22): 4561-6.

[34] Buckstein R, Imrie K, Spaner D, et al. Stem cell function and engraftment is not affected by "in vivo purging" with rituximab for autologous stem cell treatment for patients with low-grade nonHodgkin's lymphoma. Semin Oncol 1999; 26(5 Suppl 14): 115-22.

[35] Hosing C, Saliba RM, Korbling M, et al. High-dose rituximab does not negatively affect peripheral blood stem cell mobilization kinetics in patients with intermediate-grade non-Hodgkin's lymphoma. Leuk Lymphoma 2006; 47(7): 1290-4.

[36] Peggs KS, Mackinnon S. Immune reconstitution following haematopoietic stem cell transplantation. Br J Haematol 2004; 124(4): 407-20.

[37] Hegde UP, Wilson WH, White T, et al. Rituximab treatment of refractory fludarabine-associated immune thrombocytopenia in chronic lymphocytic leukemia. Blood 2002; 100(6): 2260-2.

[38] Khouri IF, Champlin RE. Nonmyeloablative stem cell transplantation for lymphoma. Semin Oncol 2004; 31(1): 22-6.

(c) Krüger et al.; Licensee Bentham Open.

This is an open access article licensed under the terms of the Creative Commons Attribution Non-Commercial License (http://creativecommons.org/licenses/ by-nc/3.0/) which permits unrestricted, non-commercial use, distribution and reproduction in any medium, provided the work is properly cited. 